\title{
David Rosenmann-Taub: Lectura de sus Silencios
}

\section{David Rosenmann-Taub: Reading his Silence}

\author{
Cristián Gómez O. \\ The University of lowa \\ Mondragon22@gmail.com
}

Resumen - Este artículo intentará poner la obra poética de David RosenmannTaub en la perspectiva de aquellas condiciones de posibilidad que hacen factible una obra como la suya. Hemos querido, así, razonar los procedimientos internos de su poesía, interrogándola en su propia retórica, pero también en lo que esa retórica silencia o se niega a decir. En el complemento de estas dos preguntas, es donde se puede desplegar el rol que cumple la historia como principio de realidad de la obra incluso si no es explícitamente mencionada.

Palabras clave: Silencio, obra, poesía, existencia, Rosenmann-Taub.

Abstract: The following paper will try to see in which perspectives a poetic work, such as the one by David Rosenmann-Taub, is feasible. The paper will try to understand the inner procedures of his poetry by questioning its own rhetoric, and by analyzing what this rhetoric denies to say or silences. As a complement to these two questions, the role of history will unravel so as to reveal its participation as a principle of reality in the work, even though it is not explicitly mentioned.

Keywords · Silence, work, poetry, existence, Rosenmann-Taub. 
Permítanme ${ }^{1}$ comenzar con una anécdota. Vamos a fecharla en 1993, pero podría haber sido 1990 ó 1996. Para el caso es lo mismo. Lo que importa aquí es un poeta por ese entonces joven, con cierto sentido de la tradición poética, Eliot de por medio, que lo llevaba al vano intento de agotar los anaqueles de cuanta biblioteca se le pusiera por delante, con la creencia de que la acumulación de títulos y nombres leídos lo llevarían tarde o temprano a encontrar o descubrir cierta epifanía que, digámoslo desde ya, aún no ha llegado. Ese joven poeta, con quien comparto nombre y apellido pero al cual le he añadido sin disimulo kilos y años por partes iguales, estaba en ese mentado año '93 que pudo ser el '96 o incluso pudo ser el '90, leyendo en los salones de la Biblioteca Nacional de Chile, allá en Santiago, allá en la Alameda, un libro de un autor ligeramente desconocido, de quien había oído algunos comentarios respecto a su pertenencia a la generación del cincuenta, que tenía algunos libros publicados y había ganado un premio a fines de los años cuarenta. El libro era Los surcos inundados, el autor, David Rosenmann-Taub.

Traigo a colación este pasaje más o menos irrelevante de mi vida, porque nos da algunas luces en torno a la recepción que ha tenido la obra de Rosenmann Taub, en especial en los últimos años. A principios de los noventa se sabía de Rosenmann Taub, pero no podría afirmar que se lo hubiera leído mucho, sus libros eran difíciles de encontrar y en general la atención (esto puede ser una generalización, pero no creo estar tan equivocado) la acaparaban Lihn, Teillier, Millán, Juan Luis Martínez, Lira, Zurita. A partir del año 2002, sin embargo, con la publicación en LOM de buena parte de los títulos publicados hasta ese entonces por Rosenmann, el panorama comenzó a cambiar. Los poetas más jóvenes comenzaron a leer a este autor que en principio no le hace la tarea fácil al lector y uno que otro homenaje se le ha hecho a su obra. También empezaron los comentarios rimbombantes, a la manera de Armando Uribe Arce, quien dijo que Rosenmann Taub era el mejor poeta vivo de toda la lengua castellana, con lo cual no avanzamos nada en absoluto en torno a la comprensión de su obra, ya que al decirlo todo, terminamos no agregando nada. Ni siquiera estaría así, de buenas a primeras, de acuerdo con el comentario de Uribe. A menos que se historice, a menos que se contextualicen la obra de Rosenmann y los comentarios en torno a ella, cualquier panegírico, por más grandilocuente que sea, conduce solo a un callejón sin salida.

Nuestra tarea, en cambio, intentará poner su obra en la perspectiva de aquellas condiciones de posibilidad que hacen factible una obra como la suya. Sé que hablar en estos términos (factibilidad, contexto, historización) es lo que menos se ha aplicado en torno a la obra de Rosenmann, toda vez que suele destacarse de manera recalcitrantemente impresionista, su lenguaje alambicado y su tendencia a la mística, sin ahondar mayormente ni en lo uno ni en lo otro, recluyendo a la postre al poeta y su obra en las categorías de hermético y profundo, pero sin profundizar, valga aquí la paradoja, ni en el primer término de la ecuación ni tampoco en el segundo.

Nos parece sin embargo que empezar nuestra tarea señalando las filiaciones de Rosenmann con la obra de César Vallejo en toda su intensidad y altura pasa, precisamente, por deslindar qué es lo que hereda Rosenmann de Vallejo y, aún mejor, qué es lo que entendemos por la obra de Vallejo.

Este texto, en una versión resumida, fue leído en el Simposio sobre César Vallejo «Voy a hablar de la esperanza», que se llevó a cabo en Hofstra University, durante el mes de octubre del 2008. De allí se desprende cierta oralidad en el ordenamiento del ensayo que he decidido mantener. 
Empezaré por un aspecto que si bien puede parecer epidérmico, en una lectura más comprensiva veremos el rol vital que juega. Me refiero a la supuesta oscuridad de la poesía de Rosenmann, al uso de neologismos y arcaísmos que - la crítica ha insistido en esto- afectarían los modos de una lectura transparente del texto:

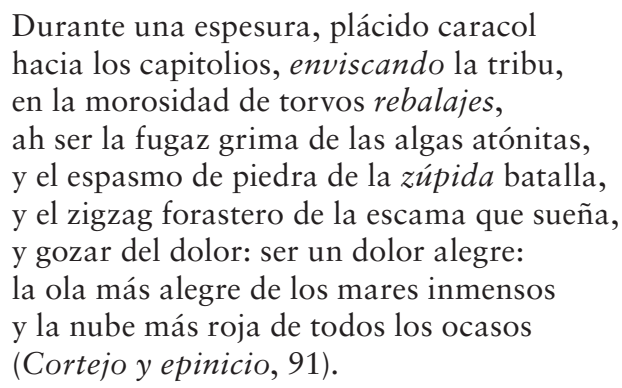

Como puede verse en un primer acercamiento, Rosenmann elegirá temas más o menos universales de la poesía occidental, tales como la muerte, la presencia y la ausencia de una figura divina, la infancia como índice tanto de nuestra plenitud y de nuestra finitud. Pese a esto, su particular modulación de los mismos lo distingue entre los poetas de su promoción y en general de toda la poesía chilena.

\begin{abstract}
Mortalidad, desconsuelo, horror, conciencia inapelable de la muerte y pérdida de una inocencia original aparecen como elementos que evocan otras fuentes de la tradición literaria nacional, española, universal. Los cultismos y manierismos propios de su estilo afloran junto con los neologismos, las palabras compuestas y las conversiones gramaticales, conformando un friso de acicaladas exploraciones verbales y pronominales, donde lo arcaico resuena siempre como novedoso y los relumbrones hirsutamente neomodernos, se insertan majestuosos en el mar heterogéneo de la frase (Nómez).
\end{abstract}

Rosenmann-Taub recurre, en Los despojos del sol (2006), según Carmen Foxley, también a la experiencia vital tal cual esta ocurre, "a episodios fugaces e insignificantes, a objetos cotidianos, fantasías, sueños, conflictos o recuerdos que están ahí, a la mano. Se establece una relación con ellos para buscar un conocimiento que supere al racional». El autor pone todas sus fichas a la intuición y la experiencia sensorial. Y la naturaleza está muy presente aquí, puesto que en su imagen se podrían encontrar huellas de lo infinito que late en lo finito. Es la opción de una escritura que se orienta a poner de relieve nuestra existencia en tanto seres espirituales, con un ojo puesto siempre en un afán de trascendencia. Se trata, en suma, de un proyecto poético que, como veremos en adelante, problematiza esa angustia ya señalada arriba por Naín Nómez, en tanto el desamparo expresado por el hablante de estos poemas se condice con lo que pareciera ser una condición esencial del ser humano, antes que una cuestión ligada a una coyuntura específica.

Otro punto que a Foxley le llama la atención es «la lucidez y coherencia significante del diseño textual». Efectivamente, la «Ananda primera» se divide en dos fragmentos de siete poemas en los que se inscribe el comienzo de la experiencia reflexiva y todo aquello que no se deja ver, a primera vista, a nuestra percepción sensorial. Sin embargo, ese infinito y ese absoluto que pareciera anhelar el hablante, se traducen en el poema a través de una serie de imágenes que mezclan referentes de primera mano (como la abuela mencionada en «La posesión», en la página 45, el ropero y el lecho por entre los que se 
asoma Dios, en la página 23) con otros que representan una indagación profunda en los límites de la identidad, como el juego del hablante y el espejo en el tercer texto de «Diario de un guijarro» (19).

En la «Ananda segunda» el panorama cambia. Estamos ahora ante una serie de interpelaciones sarcásticas y diálogos que dan un matiz dramático y terreno a la situación. La aparición de muebles y utensilios de cocina en un poema que es al mismo tiempo relato de un aprendizaje y autorreconocimiento religioso («Reconciliación», 81-83), nos habla de una segunda parte de este libro que intenta conscientemente traer aquella experiencia reflexiva hacia un contacto más directo con el mundo. Pero en ambos casos, debemos recordar que se trata de «anandas», palabra sánscrita que hasta donde hemos podido rastrear, significa alegría, felicidad suprema ${ }^{2}$. En las dos partes del libro, entonces, podemos ver no el logro de un estado de plenitud, aunque sí se tiene la percepción y el deseo de él.

Quisiera volver aquí, en este punto, a Vallejo. Para abordar la relación entre su obra y la de Rosenmann, quisiera tocar ciertos aspectos que a estas alturas parecieran «lugares comunes» alrededor de la poesía vallejiana. Si nos detenemos por ejemplo, en el coloquialismo de Vallejo y su uso de lo que Francisco Martínez García llama la frase alterada, en la que el coloquialismo del autor peruano se despliega como un abanico de bloques sintácticos. La frase coloquial se relaciona con el contexto por «inmersión, contacto o simple presencia» (cit. en O'Hara, 36); por lo tanto interesa averiguar el funcionamiento de la frase alterada en Vallejo, sea por sustitución de elementos de la misma categoría gramatical (sustantivos, adjetivos, pronombres) o por ampliación. Los ejemplos abundan y Martínez nos dice que "Lo más normal es que el sentido primitivo quede alterado, ya que se trata de un módulo al que se da nueva significación precisamente por la alteración de un elemento» (cit. en O'Hara, 36-37). Por dar solo una muestra: la sustitución de sustantivo por sustantivo la tenemos en "Salutación angélica», donde dice «...italiano ex profeso, escandinavo de aire, /español de pura bestia» (en O’Hara, 37), en lugar de la frase original que sería de pura cepa.

Este tipo de alteraciones sintácticas e idiomáticas, que encontramos a raudales tanto en Vallejo como Rosenmann, debe, no obstante, ser puesta también en otro contexto, a riesgo de conculcar los múltiples sentidos de estas escrituras. En esta perspectiva, es que nos llama de sobremanera la atención la lectura de José Cerna-Bazán, al relacionar la composición de Trilce con la situación de la postguerra peruana y la pérdida de territorios a manos del ejército chileno en la Guerra del Pacífico, de 1879.

Cerna-Bazán es capaz de articular la elección idiomática y la composición del primer poema de Trilce con las consecuencias que tuvo aquel conflicto armado en la vida del Perú. Recordemos, solo brevemente, que el guano era el fertilizante que las inversiones inglesas buscaban ávidamente para mantener el sostenido crecimiento económico de Inglaterra por aquel entonces. Dice el primer poema de este libro, que citamos in extenso:

Quién hace tanta bulla, y ni deja testar las islas que van quedando. Un poco más de consideración en cuanto será tarde, temprano, y se aquilatará mejor

el guano, la simple calabrina tesórea

2 Ananda también fue el nombre del secretario personal y amigo cercano de Buda. 
que brinda sin querer, en el insular corazón, salobre alcatraz, a cada hialóidea grupada. Un poco más de consideración, y el mantillo líquido, seis de la tarde DE LOS MÁS SOBERBIOS BEMOLES Y la península párase por la espalda, abozaleada, impertérrita en la línea mortal del equilibrio (Vallejo, 119).

El argumento de Cerna Bazán se basa en la trascendencia de un vocablo al interior del conjunto total de Trilce, lo que relaciona los niveles ideológicos y creativos de la obra en una perfecta solución de continuidad:

I begin by examining the first poem of Trilce (Trilce 1 here) which thematizes a key element of Peru's social reality in Vallejo's lifetime: the excrement of the alcatraz, guano. My focus on guano, instead of any other word in this poem is not arbitrary. Opening the book, "guano," together with "alcatraz» and the terms that refer to the bird's natural habitat («islands,» «insular,» «peninsula») saturate the poem.

From that point on, guano is projected onto a set of organic elements («cadaverine,» «liquid muck» in Trilce 1) that populate the seventy seven poems of the collection. Among those elements are material fluids like blood, sweat, tears, or cosmic and geological ones like rain and the ocean, as well as excremental materials and other substances that, in constant transformation, become organic matter or its opposite, the inorganic (Cerna-Bazán).

Desde nuestro punto de vista, lo que buscamos es explorar también en la obra de Rosenmann Taub las dimensiones históricas de una obra que no por su tono aparentemente solipsista está ajena a la historia que la posibilita. Creemos firmemente que así como la lectura de Cerna Bazán explora el tejido histórico de Trilce, la relación de Rosenmann con Vallejo tampoco se agota en meras resoluciones formales sin consideración a su contexto.

En su prólogo a Cortejo y epinicio (2002), María Nieves Alonso recalca un punto que es central para nosotros, a saber: la nostalgia de lo absoluto presente en el primer Rosenmann, ese que permea de principio a fin ese cortejo de 1949 y que fuera vuelto a escribir en 1978 y editado y revisado por tercera vez en la última edición (de LOM, en Santiago), que es la que nosotros conocemos. «Nostalgia de lo absoluto: Alonso se refiere a él como un lugar del desconsuelo y el ansia de pureza y absoluto, de la búsqueda de un lenguaje que robe alguna brizna al misterio del que tan lúcidamente han hablado Simone Weil y, también, Nietzche» (Alonso, cit en «Rosenmann-Taub», Cortejo y epinicio, 8).

Para la investigadora de Concepción, Cortejo y epinicio está tramado en torno a una ausencia. Una ausencia que es una carencia vital para el hablante. La constante presencia de la muerte, la carencia de sentido de la experiencia vital, la convivencia paradójica con lo divino. Todo el libro está recorrido por una dolorosa torsión del lenguaje que opera como decurso formal del mundo representado. Sin embargo, para que las estructuras formales de las que se vale Rosenmann las entendamos como un correlato de ese mundo representado, hay primero varias mediaciones, varios niveles que interactúan entre sí.

Así como el tejido histórico de Trilce es rastreado por Cerna-Bazán a través de su lenguaje, también entenderemos el lenguaje de Cortejo y epinicio como un síntoma, pero 
asimismo como una mediación en ese marco histórico que es donde habita la obra de Rosenmann. Marco, sin embargo, no es la mejor palabra para definir lo que intento expresar, porque da la idea de un contexto, de algo que está en torno a la obra, fuera de ella y no, como realmente suponemos, formando parte intrínseca de ella.

Una de las características más acentuadas de la obra poética completa de RosenmannTaub es su coherencia interna, su unidad. Me explico: desde Cortejo y epinicio hasta Auge podemos notar una continuidad en la construcción del poema sobre la base de distintas formas métricas y una rima asonante como patrón casi unívoco. Ni tampoco el contenido ha dejado de darnos la misma imagen de un hablante torturado ante la carencia de un elemento fundamental de la existencia, ante la conciencia lacerante de la finitud de la vida y la imposibilidad de concretar un sentido frente a esas circunstancias. Es cierto: todo esto marca un continuum creativo que ha sido una de las notas más distintivas de este poeta. No obstante ello, creemos que en el poema mismo, en la elaboración de la materia poética, se dejan ver grietas y silencios que en términos formales nos parecen la correspondencia intrínseca de esa angustia por la unidad inalcanzable. Lagunas formales que dan cuenta de las grietas de la existencia, del deseo de plenitud y de la cimposibilidad? de alcanzarla.

El silencio en el poema puede estar indicado de muy distintas maneras. Ya sea por disposición autorial, ya sea por la participación del lector en el reconocimiento del papel que juegan ellos, podemos encontrar algunas estrategias escriturales ya codificadas para ayudarnos en la tarea. Rae Armantrout, poeta y profesora norteamericana, ha especificado algunas de las formas en que el silencio «ocupa» su lugar en el poema, a saber:

1. Ella podría terminar un verso o un poema de una manera abrupta e inesperadamente.

2. Podría crear conexiones extremadamente tenues entre las distintas partes del poema.

3. Podría crear deliberadamente un efecto de inconsecuencia.

4. Podría hacer uso de la auto-contradicción o retracción.

5. Podría usar elipsis obvias.

6. Podría usar algo que coloque lo existente en una relación perceptible con algo no-existente, ausente o externo (cit. en Chirinos, 33).

Varias de estas maniobras escriturales, si no todas, podemos encontrarlas en la obra de Rosenmann, aunque difícilmente se encuentren por separado, sino una o dos al mismo tiempo como principal recurso retórico. Pero no solo se trata, como decíamos, de una iniciativa autorial, sino que los silencios en que el texto incurre (voluntaria y/o involuntariamente), también necesitan ser cabalmente comprendidos por el lector: a este respecto, Emma Sepúlveda Pulvirenti (1990) especifica algunos de los puentes que se tienden entre hablante y receptor, a saber: 1) el uso de diferentes preguntas que no tienen respuesta en el poema y que crean «un espacio paralelo de silencio que va desarrollándose en el lector por medio de la lectura» (Sepúlveda, en Chirinos, 42), las pausas que se marcan con los signos ortográficos, como por ejemplo los puntos suspensivos que llevan el silencio del hablante hasta el lector. Y, 3) «el uso de una forma dialogada en el poema: espacio de silencio que divide los parlamentos de las voces poéticas» (Chirinos, 43).

Al leer los poemas de Rosenmann, nos encontramos una y otra vez con este tipo de artefactos retóricos, los que obligan a una intervención permanente y activa del lector. Así, por ejemplo, en un poema como "Rapsodia» o «Calvarios», de Auge, nos encontramos con el uso de los puntos suspensivos para referir directamente a un afuera del poema, 
...Llaga, desde tu monte, me respondes: «Responde».

(Rosenmann Taub, «Calvarios», en Auge, 225)

Puntos suspensivos, pero también un diálogo implícito del que sólo asistimos a un fragmento. ¿Por qué calvarios y no calvario, si se habla de Dios en este libro de Rosenmann, si se habla de una Madre y un Hijo que parecieran referir a la Santísima Trinidad de la teología cristiana?, ¿cuáles son esos otros calvarios?, ¿los calvarios del hablante se pueden equiparar, así, al Calvario de Cristo?

En «Rapsodia», en cambio, el paso abismante del tiempo es referido y conjurado (fallidamente) a través del recurso de la narración de una pequeña historia, una anécdota en la que el hablante despierta al erotismo en su infancia en la contemplación de la entrepierna de una compañera de clases, Elbirita, con quien después nos enteramos que el hablante terminará casándose y teniendo con ella hijos. El hecho de que Rosenmann sea capaz de transformar esta simple anécdota en un poema que ataca temas centrales de la poesía contemporánea, nos habla del peso del lenguaje en su obra. El tiempo se cuela en el poema a través de la incerteza del hablante, que es la nota decisiva en el poema. El pasado es recordado como si hubiera ocurrido hace "Cien billones de siglos/ o ayer: no queda nadie:/ ni el señor profesor,/ ni un compañero,/ ni, por supuesto, yo» (118). El tiempo es borrado en la equivalencia de cien billones de siglos o ayer, donde esa unión de los contrarios reconcilia por la fuerza de la imagen lo que de otro modo quedaría en el espacio del absurdo: no pierde, sin embargo, el paso del tiempo, su condición de inconmensurable, a condición de que sea enunciado en el poema: el tiempo sigue igualmente presente a pesar de ser incomprensible.

Pero ojo que el dolor del hablante se enfatiza no tanto en la percepción de lo ido, sino por sobre todo en la constatación factual de la pérdida inmediata. El hablante no está del todo seguro si Elbirita ya no está debido a que «murió de pulmonía» (Rosenmann, 118) o su muerte se produjo producto del nacimiento de los últimos de sus hijos, sus mellizos. Al nacer ellos, para el hablante no solo muere Elbirita (nótese que su nombre nunca pasa a ser un Elbira de mujer madura, sino siempre con el diminutivo, tal vez como una expresión de cariño, tal vez como una forma ilusoria y obsesiva de perpetuar el tiempo): también se muere en ese parto "su secreto,/ y a mí, el campo de dicha» (Rosenmann, 118). Su secreto, id est, su entrepierna, que ella se amañaba para mostrarle a sus compañeros de clase mientras se sentaba en su pupitre. Y la dicha del hablante, que en un juego de palabras implícito refiere al campo de visión, ya que él, como el resto de los alumnos de la referida clase de antaño, «divisaban» el secreto de Elbirita. Muerte y nacimiento, final y comienzo de un deseo, tiempo original y últimos momentos. Para Octavio Paz, «Entre nacer y morir la poesía nos abre una posibilidad, que no es la vida eterna de las religiones ni la muerte eterna de las filosofías, sino un vivir que implica y contiene al morir, un ser esto que es también un ser aquello. La antinomia poética, la imagen, no nos encubre nuestra condición: la descubre y nos invita a realizarla plenamente» (155).

Quisiera aquí relacionar lo dicho por María Nieves Alonso en el prólogo de Cortejo y epinicio, en torno a la nostalgia de lo absoluto rastreable en la obra de Rosenmann, con lo que plantea Paz sobre la naturaleza misma de la poesía.

Lo sagrado se nos escapa. Al intentar asirlo, nos encontramos que tiene su origen en algo anterior y que se confunde con nuestro ser. Otro tanto ocurre con amor y poesía. Las tres experiencias son manifestaciones de algo que es la raíz misma del hombre. En las tres late 
la nostalgia de un estado anterior. Y ese estado de unidad primordial, del cual fuimos separados, del cual estamos siendo separados a cada momento, constituye nuestra condición original, a la que una y otra vez volvemos (136).

No es casual que en el que tal vez sea el mejor de sus libros, El mensajero (2003), o por lo menos en el cual se tratan con mayor ejemplaridad los temas más recurrentes de su obra: el anhelo de arraigo y absoluto en un mundo esencialmente contradictorio y efímero, el libro en el cual Rosenmann nos entregue lo que parece el reverso mismo de estos fervores, la explicación menos trascendental que podríamos esperar por parte del poeta. Allí nos dice, en un poema que no por nada se titula «Alienus», lo siguiente:

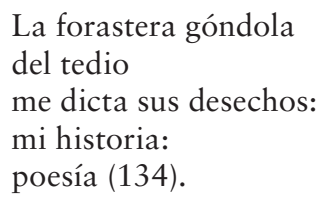

Me parece especialmente relevante que un poeta tildado de metafísico y hermético proponga tal equivalencia entre historia y poesía. Por mucho que el texto se refiera a una historia personal, ésta no puede esconder su contextualización dentro de una historia colectiva que es su previa y necesaria condición de posibilidad. La extrañeza sugerida en el título del poema nos indica una dirección probablemente incoherente con el conjunto de su escritura, en donde la requisitoria permanente es una pregunta por la esencia misma de lo humano y su relación con la divinidad. Aquí, en cambio, nos pone frente a una idea de la poesía diametralmente opuesta a la que, por ejemplo, nos entrega al concluir el libro:

Conque manso el potrillo...! Mansa coz

de chúcaro denuedo!

Por resultado, versos:

paráfrasis de Dios

(137).

Entre una y otra de estas posturas hay un silencio y/o una grieta que puede responder muchas preguntas. No intentamos llenar ese hueco sino simplemente subrayar el conflicto interno que la obra misma pareciera pasar por alto. Tal vez al destacar las contradicciones internas como la recién señalada en la escritura de Rosenmann podamos respondernos, por ejemplo, por qué El mensajero, publicado en el año 2003, lleva el subtítulo de «Cortejo y epinicio II», cuya primera parte lo antecede (por lo menos en la fecha de publicación) en cincuenta y cuatro años. Aquí hablamos de hacer una conexión entre dos obras que pertenecen a momentos muy distantes el uno del otro. En 1949 todavía no se conocía en su totalidad el Canto general (1950), de Pablo Neruda. Poemas y antipoemas sería publicado cinco años después. Un año antes, Gonzalo Rojas había publicado la primera edición, en Valparaíso, de La miseria del hombre. Jorge Teillier y Enrique Lihn aún se mantenían (prácticamente ${ }^{3}$ ) inéditos. Ergo, Cortejo y epinicio pertenece a una era donde el paradigma de la antipoesía apenas asomaba tímidamente en el panorama de la poesía chilena, sin tener todavía ni remotamente el peso que adquiriría a posteriori. El

3 Ese año de 1949 Lihn publicaría su primer libro, Nada se escurre. 
252

mensajero, en cambio, ve la luz en el apogeo y probablemente la resaca del mismo discurso, el que ya ha sido canonizado y cuyos efectos más desestabilizadores o ya se hicieron sentir o han sido continuados, extendidos y modificados por sus herederos predilectos (Lihn, Martínez, Lira): sin embargo, no podemos decir que todos estos cambios afectaran de manera sustancial la escritura de Rosenmann.

De hecho, un dato que nos parece de sumo interés es la dedicatoria con que se abre este último libro. Allí, Rosenmann dice lo siguiente:

Papá,

........ tres días antes de marcharte,

me pediste que te prometiera que revisaría

El Mensajero hasta crear el más hermoso

-real- libro.

........ Cumplir la promesa me ha exigido

cumplir tu edad (7).

De manera más o menos explícita, Rosenmann nos indica que efectivamente El mensajero es muy posterior a su antecesor, tanto que su escritura se ha cumplido en un plazo de décadas. No obstante, años más o años menos, el paso del tiempo no ha cambiado, como ya indicábamos, en su esencia la escritura de Rosenmann Taub. El mensajero, de hecho, aparece en la etapa de plena ebullición de lo que alguna crítica ha llamado generación de los '90, misma época en que empiezan a re-editarse una serie de poetas que habían sido, por distintas razones, si no olvidados, sí perdidos de vista al lado de otras figuras canónicas de nuestra poesía. De manera que no nos parece casual que estos autores, como Rosamel del Valle (quien cobra nuevos bríos con la publicación de su Obra poética [2000], en una edición a cargo de Leonardo Sanhueza, además de la antología El Orfeo del Pacífico [2000], llevada a cabo por Hernán Castellano Girón) u otros como Omar Cáceres y su Defensa del ídolo (1996), la Obra completa (2009) de Gustavo Ossorio y la reedición de autores como Enrique Gómez-Correa, Teófilo Cid y Winnett de Rokha, todos ellos demuestran una afinidad difícil de negar y que pasa precisamente por privilegiar la escritura irracional ante el paradigma reflexivo. Son los poetas de los que Nicanor Parra quiso diferenciarse al autodenominarse como parte de los «poetas de la claridad», por oposición a los de la oscuridad ${ }^{4}$.

Coincidentemente, entonces, con este proceso de recuperación de una zona de la tradición poética chilena, la obra de Rosenmann (y la publicación de El mensajero en el momento más oportuno y necesario) muestra su consonancia con esta nueva y antigua estética. A primera vista, alguien podría pensar que todo este revival se trata simplemente de una aproximación romanticista y nostálgica a la tradición chilena, una suerte de retorno al pasado en busca de respuestas que no se encontrarían en el presente. De este modo podrían también explicarse poéticas tan cercanas a los autores mencionados en poetas de las promociones más recientes, como Leonardo Sanhueza o Javier Bello, ambos editores de algunos de los rescates ya indicados. Me parece, sin embargo, que la realidad es ligeramente más complicada y que ofrece una serie de matices en los que, de

Enrique Lihn (175) recuerda que fue Tomás Lago quien le diera el espaldarazo que Parra necesitaba en el prólogo de su antología Tres poetas chilenos (1942), en un texto sintomáticamente titulado «Luz en la poesía». La antología de Lago incluía al ya mencionado Parra, junto con Óscar Castro y Victoriano Vicario. 
no reparar en ellos, estaríamos distorsionando en demasía la búsqueda que este «retorno al pasado" representa.

Esto es así porque, de hecho, me parece que no se trata de un retorno a ningún pasado. Toda esta revalorización de autores de antaño hay que entenderla como parte de un proceso mayor que la excede pero también la explica, un proceso que a su vez encuentra su punto de apoyo en este tipo de búsqueda estética.

Tal proceso requiere entender las dimensiones del cambio que Chile ha experimentado en las tres últimas décadas. Con la instalación del modelo neoliberal en Chile, por parte de la dictadura pinochetista y la continuación del modelo bajo los gobiernos democráticos, lo que en definitiva ha tenido lugar es una modificación en el paradigma con el cual la sociedad chilena se entendía a sí misma. Del Chile autosuficiente de la imaginación patrimonial resguardada por el Estado, se ha pasado a la trans-nación administrada por el mercado. Los flujos de mercancías son también intercambios de signos, marcas comerciales que han devenido tan importantes como el producto mismo que promocionan, conformando un tejido de mensajes culturales que legitiman y naturalizan una imposición del sistema de mercado que no se vive como imposición. Refiriéndose a su estudio, el académico chileno plantea que «[...] la economía política, la cultura pública y la ficción literaria se analizan y se exponen en una trama de relaciones, al interior de un dominio discursivo mayor, en que, como en una red, se hallan histórica y virtualmente entrelazados. Leo entonces el sistema de libre mercado como una formación discursiva y, subsecuentemente, como una red de signos» (13).

Cárcamo propone leer el mercado como una fábula, un relato que ha tejido su propio tramado para constituirse como una formación social sin contrapeso. Haciéndose eco de la distinción que establece Raymond Williams para el concepto gramsciano de hegemonía ${ }^{5}$, Cárcamo sostiene que desde esa perspectiva «se puede sostener que el sistema de libre mercado se constituyó, en el período estudiado [...], en una forma no sólo de dominio sino que pasó a informar el horizonte semántico y valórico del sujeto social: la economía de libre mercado como ficción social, como imaginación pública, en suma, como cultura» (249).

En esta cultura de mercado, entonces, es que la apertura de una economía abierta y «sin restricciones» pone ante la figura del autor un haz de discursos en circulación que, a pesar de las limitaciones de marketing y ventas de la lírica, no son ajenos al desenvolvimiento económico en general. Para Cárcamo, novelistas insertos en el mercado global como Isabel Allende y Luis Sepúlveda, entre otros, hacen un usufructo simbólico de lo exótico y/o de lo distante (para un público en principio no tercermundista, aunque también se dirijan por extensión a este último), «a partir de una re-utilización no mediada de los códigos del realismo mágico (a lo García Márquez) en el caso de Allende» (52) o los de la novela de aventuras y de viajes en el de Sepúlveda. Al valerse de estos idiomas

\footnotetext{
Según Williams, la hegemonía, tal y como la comprendiera Antonio Gramsci, puede distinguirse del dominio como tal. Este último «se expresa en formas directamente políticas y en tiempos de crisis por medio de una coerción directa o efectiva. Sin embargo, la situación más habitual es un complejo entrelazamiento de fuerzas políticas, sociales y culturales» (129). La hegemonía, en cambio, no es solamente el nivel superior articulado de la «ideología» ni tampoco sus formas de control consideradas habitualmente como «manipulación» o "adoctrinamiento». La hegemonía constituye todo un cuerpo de prácticas y expectativas con relación a la totalidad de la vida: nuestros sentidos y dosis de energía, las percepciones definidas que tenemos de nosotros mismos y de nuestro mundo. Es un vívido sistema de significados y valores - fundamentales y constitutivos- que en la medida en que son experimentados como prácticas parecen confirmarse recíprocamente. (131)
} 
pre-establecidos, estos autores (pero no solo ellos) pasan a ser una especie de escritoresconsumidores, que hacen uso del código estético que más les convenga y esté disponible en el supermercado de las mercaderías simbólicas.

De acuerdo a Cárcamo, el giro determinante que marca a estas narrativas sentimentales es, en lugar de un impulso político, la sintomatización de una nostalgia antes los efectos de desarraigo propios de la modernización económica en el Chile de las últimas tres décadas. Para ello recurren a una «restitución ficcional» (Cárcamo, 53) con la que se compensa la pérdida de ciertos referentes tradicionales (como la familia, la naturaleza, las costumbres hogareñas, la memoria histórica) en el nuevo escenario de un país regido en buena medida por el mercado trans-nacional.

En este contexto, la re-edición de los libros de Rosenmann Taub, su favorable recepción y la acogida que han obtenido entre las generaciones más jóvenes, indica que la sintonía de cierta zona de la producción poética más reciente con la obra del autor de País más allá y Poesiectomía, no redunda únicamente en un retorno reaccionario hacia el pasado, como si se intentara obviar el continuum histórico y el peso de la contingencia. Por el contrario, vemos en esta mirada retrospectiva un intento por enfatizar en ese desarraigo propio del Chile contemporáneo, a través de una obra como la de Rosenmann Taub (y la de los otros autores aquí incluidos) que centran su discurso en torno a esa nostalgia de absoluto que trasunta larvariamente las consecuencias del desarraigo, aun cuando todavía se haga en una escala individual. Los autores-consumidores de hoy en día, como los califica Cárcamo, revierten creativamente tal etiqueta, tal vez porque al ingresar al hipermercado de las ofertas culturales, aun cuando se encuentran al igual que otros con una amplia variedad de alternativas estilísticas, la forma en que éstas han sido asumidas por los poetas chilenos de hoy difiere de las estrategias escriturales que menciona Cárcamo. Si — para citar nuevamente a Williams - ante toda hegemonía existe o puede existir una contrahegemonía o una hegemonía alternativa (132), los poetas del Chile de hoy intentan implementar una posibilidad de diferencia al recurrir a estas prácticas culturales (re-ediciones, homenajes, lecturas públicas, estudios de los autores que intentan revivir) con las que dibujan una poética anti-celebratoria de la realidad chilena. El análisis de la nueva narrativa que hace Cárcamo, describe a los lectores de estas narrativas sentimentales como embarcándose en un viaje profiláctico hacia el pasado, espacios exóticos y/o desaparecidos, «a la manera de turistas cuyo lugar de proveniencia es el «incuestionable» aquí y ahora de la neomodernización» (53). A diferencia de estos turistas culturales, una buena parte de la poesía más reciente en Chile lo que hace es precisamente cuestionar ese aquí y ese ahora en la relectura creativa de la obra de algunos otros autores de antaño que han cobrado un renovado nuevo brío y de los que Rosenmann Taub es la evidencia de su contemporaneidad.

Hemos querido, así, razonar los procedimientos internos de la poesía de Rosenmann, interrogándola en su propia retórica, pero también en lo que esa retórica silencia o se niega a decir. En el complemento de estas dos preguntas, es donde se puede desplegar el rol que cumple la historia como principio de realidad de la obra incluso si no es explícitamente mencionada. En los silencios de la obra de Rosenmann, esas grietas que median entre una y otra definición del acto de escritura, entre Cortejo y epinicio, por una parte, y El mensajero por otra, es donde encontramos la posibilidad de explicar su escritura con relación a esa historia que lo posibilita y que, además, lo ha convertido en una figura de tal relevancia para los lectores y autores de hoy. Son esas contradicciones, esa nostal- 
gia de absoluto a la que hemos hecho referencia una y otra vez, esa nostalgia concreta y contextualizada, las que entendemos como la expresión más relevante y atingente de la obra de Rosenmann. Cerramos, entonces, con un ejemplo que ilustra nuestra exposición:

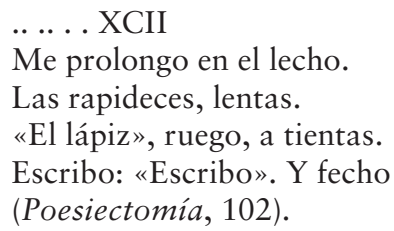

\section{REFERENCIAS}

Cáceres, Omar. Defensa del ídolo. Santiago: Lom, 1996. Medio impreso.

Cárcamo-Huechante, Luis E. Tramas del mercado: imaginación económica, cultura pública y literatura en el Chile de fines del siglo veinte. Santiago: Editorial Cuarto Propio, 2007. Medio impreso.

Cerna-Bazán, José. Capital Putamadre: Social Abstraction and Literary Representation in César Vallejo and José María Arguedas. Sitio Web.

Chirinos, Eduardo. La morada del silencio. D.F: Fondo de Cultura Económica, 1998. Medio impreso.

Foxley, Carmen. «Los despojos del sol de David Rosenmann-Taub». Sitio Web.

Lago, Tomás. Tres poetas chilenos. Santiago: Cruz del Sur, 1942. Medio impreso.

Lihn, Enrique. Nada se escurre. Santiago: Talleres gráficos Casa Nacional del Niño, 1949. Medio impreso.

—. El circo en llamas. Santiago: Lom, 1997. Medio impreso.

O’Hara, Edgar. «Vallejo: de la oreja a la garganta». Hora de Poesía 61-62 (1978). 35-40. Medio impreso.

Osorio, Gustavo. Obra Completa. Santiago: Editorial Beuvedráis, 2009. Medio impreso.

Parra, Nicanor. Poemas y antipoemas. Santiago: Nascimento, 1954. Medio impreso.

Paz, Octavio. El arco y la lira. México D.F.: F.C.E., 1990. Medio impreso.

Rojas, Gonzalo. La miseria del hombre. Valparaíso: Imprenta Roma, 1948. Medio impreso.

Rosenmann-Taub, David. Los surcos inundados. Santiago: Cruz del Sur, 1951. Medio impreso.

-. Cortejo y epinicio. Santiago: Lom, 2002. Medio impreso.

-. El mensajero. Santiago: Lom, 2003. Medio impreso.

-. El cielo en la fuente. La mañana eterna. Santiago: Lom, 2004. Medio impreso.

-. País más allá. Santiago: Lom, 2004. Medio impreso.

-. Poesiectomía. Santiago: Lom, 2005. Medio impreso.

-. Los despojos del sol. Santiago: Lom, 2006. Medio impreso.

-. Auge. Santiago: Lom, 2007. Medio impreso.

Sepúlveda Pulvirenti, Emma. «El lector de poesía: función interpretativa de los espacios del silencio». La Torre 4/14 (1990). 197-212. Medio impreso. 
256

Uribe Arce, Armando. El mayor poeta. Sitio Web.

Valle, Rosamel del. Un Orfeo del Pacífico. Santiago: Lom, 2000. Medio impreso.

-. Obra poética. Santiago: J. C. SÁEZ Editor, 2000. Medio impreso.

Vallejo, César. Obra poética completa. Madrid: Alianza Tres, 1994. Medio impreso.

Williams, Raymond. Marxismo y literatura. Trad. de Pablo di Masso. Barcelona: Ediciones Península, 1980. Medio impreso.

Recepción: 26 de abril de 2010 Aceptación: 14 de mayo de 2010 